\title{
Pulmonary nodular granulomatosis caused by inhaled vegetable particles
}

\author{
L. CROME AND J. C. VALENTINE \\ From the Departments of Pathology, the Fountain Hospital, London, \\ and the Bedford General Hospital
}

SYNOPSIS Two cases are described of nodular granulomatosis of the lungs due to starch cells derived from peas, beans, or lentils. One was an idiot of 2 years and 4 months and the other an adult who was known to have inhaled vomit during electroconvulsive treatment.

It is recognized that the hazard of inhaling food or stomach content with a possible fatal outcome is greatest in individuals whose reflexes are impaired by nervous disease, intoxication, anaesthesia, or other disturbances of brain function. Such accidents have been reported, for example, during insulin coma and electroconvulsive treatments (O'Neill, 1938; Roubier, 1951). According to Gardner (1958) food or gastric content is inhaled in about $10 \%$ of debilitated surgical patients.

Besides the instances of single inhalations, foreign material may also be aspirated repeatedly by infants or by individuals with chronic neurological disorder. An example is lipoid pneumonia caused by inhalation of liquid paraffin given as a laxative (Brimblecombe, Crome, and Tizard, 1951). In low-grade mentally defective children respiratory disorder often takes the form of inhalation pneumonia associated with collapse and, terminally, bronchopneumonia (Crome, 1951). More chronic cases show, in addition, pulmonary fibrosis.

Occasionally inhalation of certain types of food may lead to a more distinct form of nodular granulomatosis. In the cases reported by Head (1956) and Emery (1960) such lesions were caused by starchcontaining vegetable cells derived from peas, beans, or lentils. Of Head's pulmonary cases, two were mental patients who had been tube-fed, one was a man with carcinoma of the larynx and oesophagus, and the fourth a child with cleft palate. Both of Emery's patients were children with cerebral disorders.

In view of the few publications on this subject, nodular granulomatosis of the lungs caused by inhaled particles of vegetable material remains relatively unfamiliar and we have therefore deemed it worthwhile publishing two further examples of this condition.

\section{CASE REPORTS}

CASE 1 This boy, S.R.D., was the firstborn in a family otherwise free from mental or nervous disease. At the time of his birth the mother's age was 20 . She suffered from recurrent urinary infection during pregnancy, and shortly before delivery developed pre-eclamptic signs with a blood pressure of $140 / 100 \mathrm{~mm} . \mathrm{Hg}$ and albuminuria. The baby presented as a breech, which was turned at $\mathbf{3 8}$ weeks. Labour was normal and the child was born, apparently well, weighing $2.9 \mathrm{~kg}$.

At 2 months he was admitted to hospital for sudden collapse, apnoea, and hypothermia $\left(81^{\circ} \mathrm{F}\right.$.). He was resuscitated by warming and administration of fluids, the temperature gradually rising to normal. However, a week later he was noticed to have twitching movements of the limbs and face, for which he was put on phenobarbitone, with partial relief of the condition.

At 6 months he was readmitted for the myoclonic fits which became more frequent despite sedation, and was put on Mysoline, $0 \cdot 125$ g. t.d.s. He was then obviously mentally retarded. His head circumference was $41.4 \mathrm{~cm}$. (average normal for age $44 \mathrm{~cm}$. with S.D. $\doteq 1 \cdot 0$ ). His skull was somewhat asymmetrical, the left frontal region being flattened and the right ear large and abnormally low set.

At $9 \frac{1}{2}$ months he was treated for emaciation and anaemia ( $\mathrm{Hb} \mathrm{60 \% )}$ ). At 16 months his head circumference measured $43 \mathrm{~cm}$., the average normal for that age being $48 \cdot 8 \mathrm{~cm}$. with S.D. $\pm 1 \cdot 1$. The haemoglobin was $49 \%$ and he was treated with Imferon.

When admitted to the Fountain Hospital at 16 months, he was an inaccessible idiot, making a few purposeless movements in his cot, but unresponsive to stimuli. The pupils and fundi were normal, and he had alternating divergent squint. The jaw jerk was normal. There was no definite evidence of deafness. The tonic neck reflexes were only feebly demonstrable and he had virtually no 


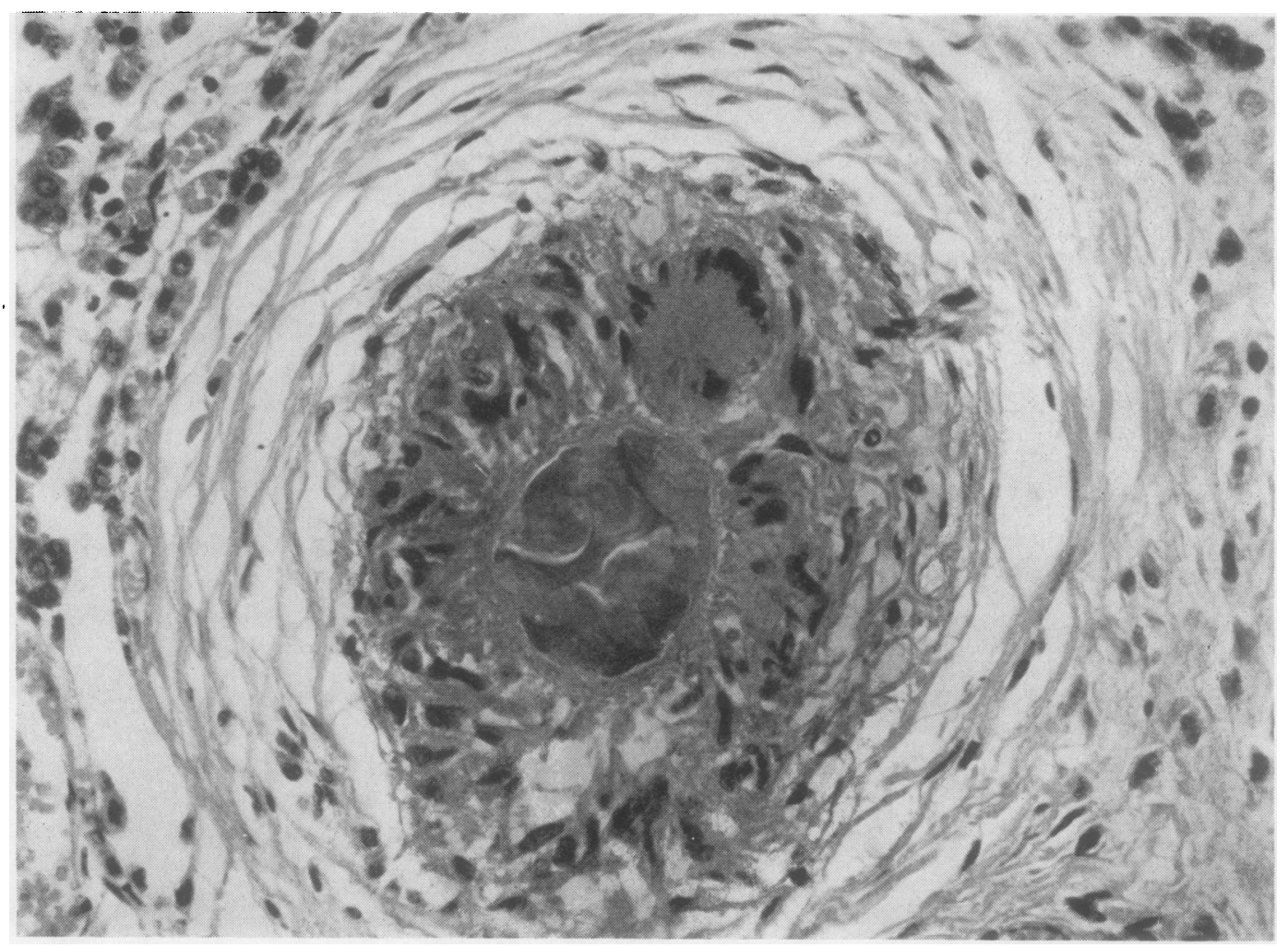

FIG. 1. Vegetable particle in the centre of the nodule, surrounded by a zone of histiocytes and foreign body giant cells. Concentric fibrosis forms the outer zone of the nodule. Haematoxylin and eosin $\times 400$.

head control. The tone in the arms was normal but placing and supporting reactions were absent. When prone, he showed a marked tendency to internal rotation of both arms, particularly the left. Muscle tone in the legs was normal, but placing reactions were absent, and the supporting reactions only feebly present. The tendon jerks were present, and both plantar responses were extensor. The Wassermann and Mantoux reactions $(1: 10,000)$ were negative. The urine was normal. Mentally, he remained an inaccessible idiot.

In the ensuing months he had frequent attacks of tonsillitis, respiratory infection, and diarrhoea. A chest radiograph taken two months before death showed increased mottling in the right upper lobe and base.

At 2 years and 4 months he developed signs of respiratory infection with slight diarrhoea. Salmonella london was isolated from the stools. He died in spite of treatment a few days later.

\section{PATHOLOGICAL FINDINGS}

LUNGS The lower lobes of both lungs (the right weighing $139 \mathrm{~g}$. and the left $116 \mathrm{~g}$.) were firm and brownish-blue. There were old interlobar adhesions, and only two lobes were present on the right side.
The cut surface showed many pale nodules up to a millimetre in diameter upon a uniformly dark rather granular background. Histologically, the nodules showed three distinct zones (Fig. 1). The outer zone was formed by concentrically arranged elongated connective tissue cells lying among delicate reticulin fibres, with little collagen and no elastic tissue. The middle zone consisted of epithelioid cells, which tended towards a radial arrangement. Some nodules also showed multinucleate giant cells in this zone. The central zone of the nodules varied. It presented in some nodules as an 'empty' lumen-like space containing, perhaps, a little amorphous thread-like P.A.S.-positive material. Other, completely formed nodules contained folds of a P.A.S.-positive membranous structure. Some nodules showed centrally a globular body formed by vegetable cells with rather indistinct boundaries. This body was P.A.S.-positive, some of its portions staining blue with Lugol's iodine. Comparison with the microscopic appearances of cooked purees of commonly used pulses showed that the material in the nodules was derived 


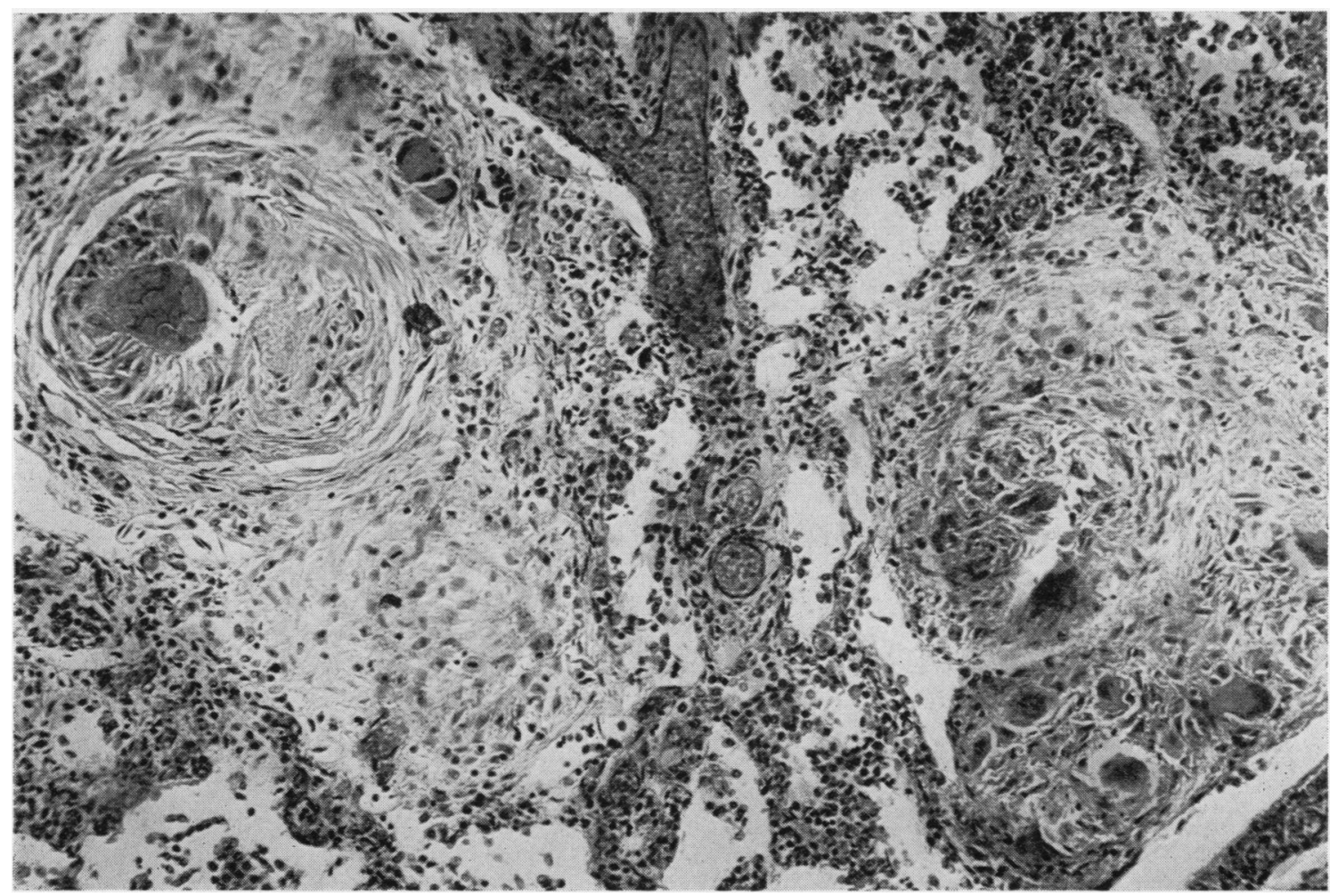

FIG. 2. A typical nodule on the left and less typical nodules elsewhere. Haematoxylin and eosin $\times 150$.

from beans, peas, or lentils. More precise identification of the partially altered and digested material proved impossible. (It is perhaps also worth stating that in many of the tangentially cut nodules the plane of the section had bypassed the central portion.)

There were also in the vicinity of the nodules less typically formed structures, some of which contained foreign body giant cells as well as multinucleate cells resembling the Langhans cells of tuberculosis (Fig. 2). However, tuberculosis could be ruled out by the negative Mantoux reaction, while tubercle bacilli were not found in any of the Ziehl-Neelsen stained preparations of the histological sections examined. Many intra-alveolar histiocytes were present between the nodules and some of these contained sudanophil cytoplasmic inclusions. A few multinucleate cells were also present in the alveolar exudate, as well as inhaled fragments of bronchial mucosa, columnar cells of respiratory type, and mucus. Some areas showed, in addition, early bronchopneumonia, and others focal collapse with or without interstitial infiltration by lymphocytes and plasma cells.
BRAIN The brain was small, weighing $660 \mathrm{~g}$., the average normal for the age being $1,100 \mathrm{~g}$. The cerebellum was relatively large, weighing, together with the brain-stem, $105 \mathrm{~g}$. The meninges were clear. The cerebral tissue was somewhat indurated, and the gyri showed slight sclerosis with an indistinct granular puckering of their surfaces.

Representative blocks of the brain were embedded in paraffin and sections stained by the usual methods. Frozen sections were used for fat staining, Kulschitzky-Pal, and silver impregnation methods. The chief histological changes were fibrous gliosis of the cerebral white matter with some astrocytic hyperplasia. Many nerve cells showed varying degrees of degeneration and there appeared to be slight general paucity of cortical neurons.

Other organs showed no noteworthy change.

CASE 2 H.N., aged 58, a motor driver, had a 'nervous breakdown' in 1954 and was investigated in hospital in 1957 for long-standing indigestion. A persistent deformity was found in the duodenal cap, and he was treated medically. In May 1960 he was in a mental hospital for a 
further 'nervous breakdown' for which he was being given electroconvulsive therapy. During one of the treatments vomit appeared through his nostrils. He was turned on his left side, head down, and given prophylactic Seclopen. During the next week he developed breathlessness and felt unwell, and a radiograph showed shadowing in the lingula but no radiological abnormality elsewhere in the lungs. Slight pyrexia continued in spite of the administration of broad-spectrum antibiotics, and three weeks after the inhalation he suddenly became much worse with a swinging temperature and headache and was admitted to Bedford General Hospital. On admission he was very ill with rapid shallow respirations, and crepitations over the left lower and middle zones. There was a moderate leucocytosis of $12,000 / \mathrm{c}$.mm. with 8,520 polymorphs and 960 eosinophils. A radiograph of the chest now showed consolidation of the whole of the left lung and patchy opacity of the right base. In spite of vigorous antibiotic therapy, steroids, and digitalis he died on the day following admission.

It is known that beans were on the menu on the day on which he had inhaled the vomit.

\section{PATHOLOGICAL FINDINGS}

The body was of a well-built, slightly obese man. There was a moderate amount of turbid fluid in the left pleural cavity. The right pleural cavity and pericardium were free of fluid. There was right ventricular hypertrophy $(6 \mathrm{~mm}$.), the heart weighing $355 \mathrm{~g}$., but being otherwise normal. The spleen was slightly enlarged (178 g.), soft and with enlarged Malpighian bodies.

Both lungs were heavy (L. 1,305 g., R. 860 g.), slatey-blue externally and nodular to touch. On section, numerous small irregular greyish-yellow areas measuring a few millimetres across were fairly evenly scattered throughout both lungs. They were quite firm but appeared to contain some purulent material. They resembled miliary tubercles or small pyogenic abscesses without being quite typical of either. The intervening lung tissue showed only oedema. No other significant findings were noted.

Microscopically there was an organizing fibrinous exudate with moderate mononuclear cell infiltration throughout the lung. The nodules (Fig. 3) consisted of a central polymorph-containing zone surrounded by a ring of histiocytes which sometimes formed multinucleate giant cells. Externally there was a zone of concentric fibrosis. Many of these lesions at their centres contained an oval or spherical vegetable body with a lobulated internal structure. They were strongly Schiff-positive by the P.A.S. method and parts of them gave also a blue reaction with iodine.

\section{DISCUSSION}

The lesions in the above two cases resemble those previously described and illustrated by Head and by

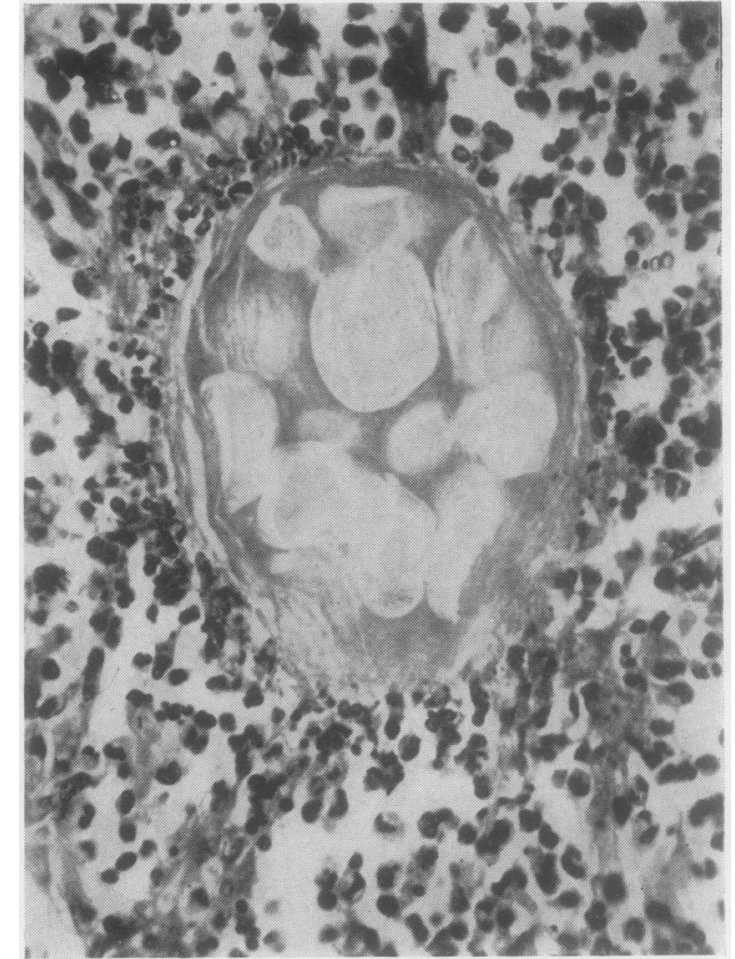

FIG. 3. The centre of a nodule containing vegetable particles and surrounded by a zone of polymorphs. Haematoxylin and eosin $\times 450$.

Emery. Similar lesions may also occur in the stomach wall (Sherman and Moran, 1954). However, in spite of the morphological resemblance, it is impossible to be certain that the inhaled material is identical in all cases. It is difficult enough to distinguish under a microscope finely ground and cooked particles of different pulses from each other, and this becomes well nigh impossible after the material has undergone a varying amount of digestion in the stomach before inhalation and further change within the lungs. Furthermore, in Case 1, some of the inhaled matter was not foreign but autochthonous, while the inhaled foreign matter included protein and fatty substances in addition to the discrete vegetable particles. In Case 2, the vegetable matter was probably derived from beans.

It is probable that, in view of the heterogeneity of the lesions and the clinical history, inhalation had occurred on repeated occasions in Case 1. In Case 2 the inhalation was evidently a single incident during electroconvulsive therapy. If so, it is difficult to explain why the lesions appeared to progress radiologically, being first seen in the lingula of one lung and then spreading to the other. A possible explana- 
tion is that the lingula had received a larger dose of food particles, and that the reactive granulomatosis was therefore denser and earlier in that part of the lung.

Since particles of vegetable matter of all kinds must often be inhaled, it is curious that only the pulses should have hitherto been incriminated as a cause of severe pulmonary granulomatosis. Two possible factors may account for this. First, the pulses are commonly cooked to a puree or soup form, so that when aspiration occurs the cells are liable to be widely disseminated throughout the lung. Secondly, these vegetable particles may also possess some hitherto unidentified toxic property generating an unusually vigorous nodular tissue reaction.
We wish to record our thanks to Dr. N. Wynn-Williams and to our colleagues at the Fountain Hospital for access to their notes. Professor W. St. C. Symmers has given us valuable advice.

\section{REFERENCES}

Brimblecombe, F. S. W., Crome, L., and Tizard, J. P. M. (1951). Arch. Dis. Childh., 26, 141.

Crome, L. (1951). J. ment. Sci., 97, 792.

Emery, J. L. (1960). Proc. roy. Soc. Med., 53, 952.

Gardner, A. M. N. (1958). Quart. J. Med., 27, n.s., 227.

Head, M. A. (1956). J. clin. Path., 9, 295.

O'Neill, F. J. (1938). Psychiat. Quart., 12, 455.

Roubier, C. (1951). J. Mét. Lyon, 32, 707.

Sherman, F. E., ard Moran, T. J. (1954). Amer. J. clin. Path., 24, 415. 